\title{
Vishwanath Pandit, Ethics, Economics and Social Institutions
}

\author{
Springer Science and Business Media Singapore, 2016, pp. \\ xxii + 169, $€$ 114.99, ISBN: 9789811008993
}

\author{
Pulin B. Nayak ${ }^{1}$
}

Published online: 14 December 2017

(C) The Author(s) 2017. This article is an open access publication

This book is concerned with the abiding link between ethics and economics. The author, Vishwanath Pandit, has had a distinguished career as Professor of Economics at the Delhi School of Economics, where he taught macroeconomics, among other papers, to generations of students. After his Master's at the DSE he worked for his doctorate with Nobel laureate Lawrence Klein at the University of Pennsylvania. He was associated, along with late Professor K Krishnamurthy of the Institute of Economic Growth, with one of the earliest versions of an economy wide macro modelling exercise for India, which has been profitably used by later generations of scholars. After his retirement from the DSE, Professor Pandit joined the Sri Sathya Sai Institute of Higher Learning in 2001 and set up the Department of Economics at the Deemed University, and later also served a term as its Vice Chancellor.

This book was written while Professor Pandit held a National Fellowship during 2013-14 awarded by the Indian Council of Social Science Research. The key message of the book is that ethics and morality are intrinsically linked to economics. Indeed, economics as a subject had been very much part of the moral sciences tripos in Cambridge University. Following the influential writings of Lionel Robbins in the 1930s, a broad consensus emerged to keep value judgements or ethical concerns away from the realm of economics. This was predicated substantially on the difficulty that lay in making interpersonal comparisons of utility, and the central core of new welfare economics was based on the Paretian notion of efficiency.

Indeed, the above view has had its sway well into contemporary times. Yet it would not be unfair to say that the markedly original writings of the late Anthony Atkinson, as well as the extensive writings of John Rawls and Amartya Sen, among others, has again given a fillip to studies that directly address issues of ethics and

Pulin B. Nayak

pulin.nayak@gmail.com

1 Centre for Development Economics, Delhi School of Economics, Delhi, India 
distributive justice. Professor Pandit begins the study from the foundational contributions of Immanuel Kant and Adam Smith. He underlines the fact that Smith, while assigning primacy to the allocative efficiency role of the market mechanism in his 'Wealth of Nations', was also careful to emphasise the importance of sympathy in human action in his 'Theory of Moral Sentiments'. There is also an elaborate discussion on the Kantian notion of the 'categorical imperative', which enjoins all beings to conform to the moral law. The author then makes an interesting presentation of the ethical dimensions in the writings of Marx and Keynes.

It is possible to hold that the two fundamental theorems of welfare economics contain the essence of the construct of neo classical general equilibrium theory. The first theorem, viz., all competitive equilibrium allocations are Pareto efficient, is essentially a statement of the efficiency property of perfect competition. But it is the second theorem that introduces the possibility of considering distributive, or ethical, issues of distribution, and to that extent enables a policy maker to separate the allocative and distributive functions of public policy. There is a careful discussion of this issue in the third chapter. The book then takes the reader through the issue of aggregation of preferences in the Arrowian framework, and in that context examines the notions of equity due to Rawls and Hammond.

What is it that a rational human being seeks to maximise? If it is happiness, and if happiness, or utility, generation is a function of the goods and services a person actually consumes, can we then conclude that with more goods and services and, therefore, with more income, human happiness increases? At one point the author observes: 'It has been methodically established by researchers that there is no clear link between growing prosperity and the feeling of increasing subjective well-being' (p. 74). The Easterlin paradox states that life satisfaction increases as income increases but only up to a point, beyond which the marginal gain in satisfaction may be zero or negative. In his Nicomachaen Ethics, Aristotle had argued that happiness lies in virtuous activities. Both these notions are considered in some detail. The author then takes us to a consideration of relative income hypothesis, which suggests that it is a higher relative income that would enable a person to have a higher level of consumption and thereby greater happiness.

The key aspect that distinguishes this work from other tracts on similar themes is the role the author assigns to religion. If there is one major Indian public personality for whom religion was an integral part of public action, it would have to be Mohandas K Gandhi. Gandhiji is known to have stated that for him economics and ethics are indistinguishable. For him economics was about making the right ethical or moral choices. In this context, Gandhiji had advanced the notion of 'trusteeship' which suggested that capitalists should hold wealth not for their selfish consumption but for employing it for the social good. This had been critiqued by a number of authors including Jayaprakash Narayan, Jawaharlal Nehru and Gunnar Myrdal.

The author goes on to suggest that it is three sets of thoughts or 'missions' ( $\mathrm{p}$. 148) which he finds worthwhile, and which constitute his ethical view of the economy and life more generally. The first is the commitment to truth and nonviolence as propagated by Gandhi. The second has to do with the notion of 'nonduality', or adwaita, as advocated by Ramakrishna and his disciple Vivekananda. The third and the last is the advocacy of 'pure love' as suggested by Sri Satya Sai 
Baba. The last element possibly is a long distance away from the original project of the rest of the book which is a discourse on fairly mainstream economic issues focussed on the attainment of the maximum happiness for the economy at large.

Yet one has to accept that these are the essential constituents of the ethical notion of the economy and society as envisaged by the author and one can hardly take exception to this. As pointed out by Professor Prasanta K Pattanaik in the foreword to this book, for the kind of enterprise the book is engaged in, it is often more important to ask the right kind of questions, and the value of a work is often not to be judged in terms of the definitive answers that have been arrived at, but in terms of the questions it has been able to pose. Judged on that yardstick, the book would seem to succeed admirably.

Open Access This article is distributed under the terms of the Creative Commons Attribution 4.0 International License (http://creativecommons.org/licenses/by/4.0/), which permits unrestricted use, distribution, and reproduction in any medium, provided you give appropriate credit to the original author(s) and the source, provide a link to the Creative Commons license, and indicate if changes were made. 